\title{
PENENTUAN PREMI TAHUNAN PADA ASURANSI JOINT LIFE DENGAN MENGGUNAKAN ANUITAS REVERSIONARY
}

\author{
IHSAN KAMAL, DODI DEVIANTO, FERRA YANUAR \\ Program Studi Matematika, \\ Fakultas Matematika dan Ilmu Pengetahuan Alam, Universitas Andalas, \\ Kampus UNAND Limau Manis Padang, Indonesia, \\ ihsan.kamal3@gmail.com
}

\begin{abstract}
Abstrak. Anuitas reversionary merupakan suatu anuitas untuk peserta asuransi jiwa yang dimulai pada saat salah satu peserta yang lain dalam satu kontrak asuransi meninggal dunia hingga akhir tahun kontrak yang telah ditetapkan. Anuitas reversionary ini merupakan penerapan dari anuitas janda dan anuitas yatim, dimana anuitas janda adalah anuitas yang dibayarkan kepada istri pada waktu suaminya meningggal, dan anuitas yatim (orphans annuity) adalah anuitas yang dibayarkan dengan syarat salah satu dari orang tuanya meninggal dunia. Premi tahunan dengan menggunakan anuitas reversionary dapat ditentukan dengan mengkombinasikan status joint life pada peserta asuransi jiwa bersama.
\end{abstract}

Kata Kunci: Asuransi jiwa bersama, status joint life, anuitas reversionary, premi

\section{Pendahuluan}

Pada hakekatnya, asuransi jiwa merupakan suatu bentuk kerja sama yang bertujuan untuk menghindarkan atau mengurangi risiko yang diakibatkan oleh risiko kematian, risiko hari tua, dan risiko kecelakaan. Berdasarkan jumlah tertanggungnya, asuransi jiwa dibedakan menjadi dua, yaitu asuransi jiwa perorangan, dan asuransi jiwa bersama. Pada asuransi jiwa perorangan, jumlah tertangungnya hanya satu orang, sedangkan jumlah tertanggung pada asuransi jiwa bersama lebih dari satu orang [1]. Dari berbagai macam jenis asuransi jiwa yang tersedia saat ini, pada dasarnya ada empat jenis asuransi jiwa, yaitu asuransi jiwa seumur hidup, asuransi jiwa berjangka, asuransi jiwa dwiguna murni, asuransi jiwa dwiguna [2]. Perbedaan dari keempat jenis asuransi jiwa ini terletak pada lamanya kontrak asuransi dan jenis kontrak yang ditawarkan oleh perusahaan asuransi. Asuransi jiwa bersama terbagi atas dua, yaitu asuransi jiwa joint life dan asuransi jiwa last survivor. Asuransi jiwa joint life merupakan asuransi jiwa bersama yang pembayaran preminya sampai kematian pertama dari pesertanya, sedangkan asuransi jiwa last survivor merupakan asuransi jiwa yang pembayaran preminya dilakukan sampai kematian terakhir dari pesertanya. Kemudian dalam asuransi juga dikenal istilah anuitas yang merupakan sederetan pembayaran berkala dalam jumlah tertentu, yang dilakukan setiap periode tertentu dan selama waktu tertentu.

Pada asuransi jiwa bersama joint life, premi yang dibayarkan oleh peserta asu- 
ransi akan berakhir atau berhenti jika salah satu dari peserta asuransi tersebut meninggal dan kemudian ahli waris mendapatkan santunan dari perusahaan asuransi. Asuransi jiwa bersama joint life ini juga bisa dikombinasikan dengan anuitas reversionary. Artinya, setelah salah satu peserta asuransi meninggal dunia dan ahli waris mendapatkan santunan, tetapi peserta yang masih hidup akan tetap melanjutkan pembayaran premi hingga akhir kontrak asuransi dengan status joint life.

Dalam paper ini akan dibahas tentang premi yang harus dibayarkan peserta asuransi joint life yang melanjutkan kontrak asuransi setelah salah satu dari peserta meninggal dunia. Dalam hal ini penulis hanya membatasi hingga tiga orang tertanggung (peserta asuransi) yang berusia $x, y$, dan $z$ tahun.

\section{Peluang Hidup Gabungan}

Terdapat dua orang peserta asuransi jiwa bersama joint life berusia $x$ dan $y$ tahun dengan asumsi $(x)$ dan $(y)$ akan tetap hidup selama $n$ tahun adalah saling bebas, maka peluang hidup gabungannya adalah [3]:

$$
{ }_{n} p_{x y}={ }_{n} p_{x} \cdot{ }_{n} p_{y}
$$

Peluang salah satu dari dua orang yang berusia $x$ dan $y$ tahun akan meninggal dalam kurun waktu $n$ tahun adalah [3]:

$$
{ }_{n} q_{x y}=1-{ }_{n} p_{x y}
$$

Sedangkan peluang salah satu diantara dua orang masing-masing berusia $x$ dan $y$ tahun pertama kali meninggal dalam selang waktu $[n, n+1]$ tahun adalah [3]:

$$
{ }_{n} \mid q_{x y}={ }_{n} p_{x y}-{ }_{n+1} p_{x y}
$$

dan didefinisikan juga bahwa [4]

$$
{ }_{n} q_{x y}=q_{x y}+{ }_{1}\left|q_{x y}+\ldots{ }_{n-1}\right| q_{x y}
$$

Untuk peserta asuransi jiwa bersama last survivor, maka peluang dua orang yang masing-masing berusia $x$ dan $y$ tahun akan meninggal dalam $n$ tahun adalah $[3]:$

$$
{ }_{n} q_{\overline{x y}}={ }_{n} q_{x} \cdot{ }_{n} q_{y}
$$

Dengan menggunakan persamaan (2.5) diatas dapat diperoleh peluang sedikitnya satu orang dari dua orang yang berusia $x$ dan $y$ tahun akan tetap hidup dalam kurun waktu $n$ tahun, yaitu:

$$
{ }_{n} p_{\overline{x y}}={ }_{n} p_{x}+{ }_{n} p_{y}-{ }_{n} p_{x y}
$$

Sedangkan peluang dua orang yang berusia $x$ dan $y$ tahun akan meninggal keduaduanya dalam jangka waktu $[n, n+1]$ adalah:

$$
{ }_{n} \mid q_{\overline{x y}}={ }_{n} p_{\overline{x y}}-{ }_{n+1} p_{\overline{x y}} .
$$

Didefinisikan juga bahwa [3]:

$$
{ }_{n} q_{\overline{x y}}=q_{\overline{x y}}+{ }_{1}\left|q_{\overline{x y}}+\ldots+{ }_{n-1}\right| q_{\overline{x y}} .
$$


114 Ihsan Kamal dkk.

\section{Simbol Komutasi}

Berikut ini merupakan simbol-simbol komutasi yang biasa digunakan untuk memudahkan perhitungan dalam tabel mortalitas pada asuransi jiwa perorangan, yaitu $[6]$ :

$$
\begin{aligned}
D_{x} & =v^{x} l_{x} \\
N_{x} & =D_{x}+D_{x+1}+D_{x+2}+\ldots+D_{\omega} \\
C_{x} & =v^{x+1} d_{x} \\
M_{x} & =C_{x}+C_{x+1}+C_{x+2}+\ldots+C_{\omega}
\end{aligned}
$$

Sedangkan untuk asuransi jiwa bersama, simbol komutasi gabungan yang digunakan didefinisikan sebagai berikut [4]:

$$
\begin{aligned}
D_{x y} & =v^{\frac{x+y}{2}} l_{x y} \\
N_{x y} & =D_{x y}+D_{x+1: y+1}+D_{x+2: y+2}+\ldots+D_{\omega \omega} \\
C_{x y} & =v^{\frac{x+y}{2}+1} d_{x y} \\
M_{x y} & =C_{x y}+C_{x+1: y+1}+C_{x+2: y+2}+\ldots+C_{\omega \omega}
\end{aligned}
$$

dimana $\omega$ merupakan usia tertinggi yang dicapai peserta asuransi, dan $v$ menyatakan faktor diskon yaitu:

$$
v=\frac{1}{1+i}
$$

dan $i$ merupakan tingkat suku bunga.

\section{Anuitas pada Asuransi Jiwa Perorangan}

Asuransi jiwa perorangan adalah suatu perjanjian asuransi yang berhubungan dengan suatu keadaan hidup matinya seseorang yang hanya ditentukan oleh satu orang saja. Anuitas pada asuransi jiwa perorangan merupakan serangkaian pembayaran yang dilakukan selama seseorang tertentu masih hidup dan tergantung pada hidup matinya seseorang. Nilai tunai anuitas hidup pada asuransi jiwa perorangan dapat dirumuskan sebagai berikut [2]:

(1) Nilai tunai anuitas hidup awal seumur hidup untuk seseorang berusia $x$ tahun dengan pembayaran sebesar 1 rupiah adalah:

$$
\ddot{a}_{x}=\sum_{t=0}^{\omega-x} v^{t}{ }_{t} p_{x}=\frac{N_{x}}{D_{x}}
$$

(2) Nilai tunai anuitas hidup akhir seumur hidup untuk seseorang berusia $x$ tahun dengan pembayaran sebesar 1 rupiah adalah:

$$
a_{x}=\sum_{t=1}^{\omega-x} v^{t}{ }_{t} p_{x}=\frac{N_{x+1}}{D_{x}}
$$


(3) Nilai tunai anuitas hidup awal berjangka $n$ untuk seseorang berusia $x$ tahun dengan pembayaran sebesar 1 rupiah adalah:

$$
\ddot{a}_{x: \bar{n} \mid}=\sum_{t=0}^{n-1} v^{t}{ }_{t} p_{x}=\frac{N_{x}-N_{x+n}}{D_{x}}
$$

(4) Nilai tunai anuitas hidup akhir berjangka $n$ untuk seseorang berusia $x$ tahun dengan pembayaran sebesar 1 rupiah adalah:

$$
a_{x: \overline{n \mid}}=\sum_{t=1}^{n} v^{t}{ }_{t} p_{x}=\frac{N_{x+1}-N_{x+n+1}}{D_{x}}
$$

\section{Anuitas Hidup pada Asuransi joint Life}

Asuransi joint life menanggung dua jiwa atau lebih, dan perhitungan premi pada status hidup gabungan untuk asuransi joint life ini berkaitan dengan hidup dan matinya dua orang tertanggung atau lebih, sehingga anuitas yang digunakan adalah anuitas hidup gabungan joint life. Anuitas joint life adalah suatu rangkaian pembayaran oleh dua tertanggung atau lebih, dimana pembayaran terhenti apabila salah satu tertanggung meninggal dunia. Nilai tunai anuitas hidup pada asuransi joint life dapat dirumuskan sebagai berikut [3]:

(1) Nilai tunai anuitas hidup awal joint life seumur hidup untuk seseorang berusia $x$ tahun dengan pembayaran sebesar 1 rupiah adalah:

$$
\ddot{a}_{x y}=\sum_{t=0}^{\omega} v^{t}{ }_{t} p_{x y}=\frac{N_{x y}}{D_{x y}}
$$

(2) Nilai tunai anuitas hidup akhir joint life seumur hidup untuk seseorang berusia $x$ tahun dengan pembayaran sebesar 1 rupiah adalah:

$$
a_{x y}=\sum_{t=1}^{\omega} v^{t}{ }_{t} p_{x y}=\frac{N_{x+1: y+1}}{D_{x y}}
$$

(3) Nilai tunai anuitas hidup awal joint life berjangka untuk seseorang berusia $x$ tahun dengan pembayaran sebesar 1 rupiah adalah:

$$
\ddot{a}_{x y: \bar{n} \mid}=\sum_{t=0}^{n-1} v^{t}{ }_{t} p_{x y}=\frac{N_{x y}-N_{x+n: y+n}}{D_{x y}}
$$

(4) Nilai tunai anuitas hidup akhir joint life berjangka untuk seseorang berusia $x$ tahun dengan pembayaran sebesar 1 rupiah adalah:

$$
a_{x y: \bar{n} \mid}=\sum_{t=1}^{n} v^{t}{ }_{t} p_{x y}=\frac{N_{x+1: y+1}-N_{x+n+1: y+n+1}}{D_{x y}}
$$

\section{Anuitas Reversionary}

Misalkan $(x)$ merupakan orang pertama yang berusia $x$ tahun dan $(y)$ merupakan orang kedua yang berusia $y$ tahun, $(x)$ dan $(y)$ merupakan peserta asuransi. Anuitas reversionary dapat dibedakan menjadi dua kasus [3]: 
(1) Untuk kasus pertama, anuitas reversionary adalah serangkaian pembayaran yang dimulai pada akhir tahun kematian $(x)$ jika $(y)$ masih hidup dan akan hidup sampai akhir kontrak asuransi yang telah ditetapkan, nilai sekarang dari anuitas reversionary untuk kasus pertama ini dinotasikan dengan $a_{x|y: \bar{n}|}$, yaitu

$$
a_{x \mid y: \overline{n \mid}}=\sum_{t=1}^{n}{ }_{t-1} \mid q_{x} v^{t}{ }_{t} p_{y} \ddot{a}_{y+t: \overline{n-t+1 \mid}}=a_{y: \overline{n \mid}}-a_{x y: \overline{n \mid}}
$$

(2) Untuk kasus kedua, anuitas reversionary adalah serangkaian pembayaran yang dimulai pada akhir tahun kematian $(y)$ jika $(x)$ masih hidup dan akan hidup sampai akhir kontrak asuransi yang telah ditetapkan, nilai sekarang dari anuitas reversionary untuk kasus kedua ini dinotasikan dengan $a_{y \mid x: \overline{n \mid}}$.

$$
a_{y \mid x: \overline{n \mid}}=\sum_{t=1}^{n}{ }_{t-1} \mid q_{y} v^{t}{ }_{t} p_{x} \ddot{a}_{x+t: \overline{n-t+1 \mid}}=a_{x: \overline{n \mid}}-a_{x y: \overline{n \mid}}
$$

\section{Anuitas Reversionary pada Asuransi Jiwa Bersama Joint Life}

Misalkan $(x),(y)$, dan $(z)$ adalah peserta asuransi, dimana $(x)$ merupakan orang yang berusia $x$ tahun, $(y)$ merupakan orang yang berusia $y$ tahun, dan $(z)$ merupakan orang yang berusia $z$ tahun. Berikut ini akan diuraikan nilai tunai anuitas reversionary pada asuransi jiwa bersama joint life, yaitu [3]:

(1) Jika $(y)$ dan $(z)$ yang hidup bersamaan dengan status joint life dimulai pada akhir tahun polis pada waktu $(x)$ meninggal, yang masih hidup adalah $(y)$ dan (z) sampai pada akhir tahun polis ke- $n$. Jika pembayaran anuitas setiap akhir periode selama $n$ tahun dengan bunga $i$ per periode adalah 1 rupiah, maka nilai tunai anuitas untuk $y$ dan $z$ adalah [3]:

$$
a_{x \mid y z: \overline{n \mid}}=\sum_{t=1}^{n}{ }_{t-1} \mid q_{x} v^{t}{ }_{t} p_{y z} \ddot{a}_{y+t, z+t: \overline{n-t+1 \mid}}=a_{y z: \bar{n} \mid}-a_{x y z: \overline{n \mid}}
$$

(2) Jika $(x)$ dan $(y)$ yang hidup bersamaan dengan status joint life, jika di antara $(x)$ dan $(y)$ ada yang meninggal dunia (yang manapun juga), pada akhir tahun polis tersebut jatuh tempo anuitas untuk $(z)$. Jika pembayaran anuitas setiap akhir periode selama $n$ tahun dengan bunga $i$ per periode adalah 1 rupiah,maka nilai tunai anuitas untuk $z$ adalah [3]::

$$
a_{x y|z: \bar{n}|}=\sum_{t=1}^{n}{ }_{t-1} \mid q_{x y} v^{t}{ }_{t} p_{z} \ddot{a}_{z+t: \overline{n-t+1 \mid}}=a_{z: \bar{n} \mid}-a_{x y z: \bar{n} \mid}
$$

\section{Premi Tahunan untuk Asuransi Jiwa Bersama dengan Menggunakan Anuitas Reversionary}

Premi tahunan adalah premi yang dibayarkan pada setiap awal permulaan tahun oleh peserta asuransi. Pada anuitas reversionary, premi tahunan mulai dibayar setelah salah satu atau dua orang dari peserta asuransi jiwa bersama meninggal dunia sampai akhir tahun ke- $n$. Premi tahunan akan berhenti jika terjadi resiko terhadap peserta asuransi tersebut. 
(1) Jika $(x)$ dan $(y)$ hidup bersamaan, maka

a. Nilai tunai anuitas reversionary untuk $(y)$ setelah $(x)$ meninggal dunia dinotasikan dengan $a_{x|y: \bar{n}|}$. Pembayaran premi tahunan untuk anuitas $a_{x \mid y: \overline{n \mid}}$ sebesar 1 rupiah yang dinotasikan dengan $P\left(a_{x|y: \bar{n}|}\right)$ adalah [3]:

$$
P\left(a_{x \mid y: \overline{n \mid}}\right)=\frac{a_{x \mid y: \overline{n \mid}}}{\ddot{a}_{x y: \overline{n \mid}}}
$$

Berdasarkan persamaan (6.1), maka

$$
P\left(a_{x \mid y: \overline{n \mid}}\right)=\frac{a_{y: \overline{n \mid}}-a_{x y: \overline{n \mid}}}{\ddot{a}_{x y: \overline{n \mid}}}
$$

b. Nilai tunai anuitas reversionary untuk $(x)$ setelah $(y)$ meninggal dunia dinotasikan dengan $a_{y|x: \bar{n}|}$. Pembayaran premi tahunan untuk anuitas $a_{y|x: \bar{n}|}$ sebesar 1 rupiah yang dinotasikan dengan $P\left(a_{y|x: \bar{n}|}\right)$ adalah [5]:

$$
P\left(a_{y \mid x: \overline{n \mid}}\right)=\frac{a_{y \mid x: \overline{n \mid}}}{\ddot{a}_{x y: \bar{n} \mid}}
$$

Berdasarkan persamaan (6.2), maka

$$
P\left(a_{y \mid x: \overline{n \mid}}\right)=\frac{a_{x: \overline{n \mid}}-a_{x y: \bar{n} \mid}}{\ddot{a}_{x y: \bar{n} \mid}}
$$

(2) Premi tahunan pada asuransi jiwa bersama joint life dengan menggunakan anuitas reversionary

a. Jika $(y)$ dan $(z)$ yang hidup bersamaan dengan status joint life dimulai pada akhir tahun polis pada waktu $(x)$ meninggal dunia, yang masih hidup adalah $(y)$ dan $(z)$ sampai pada akhir tahun polis ke- $n$, nilai tunai anuitasnya dinotasikan dengan $a_{x|y z: \bar{n}|}$. Pembayaran premi tahunan untuk anuitas $a_{x|y z: \bar{n}|}$ sebesar 1 rupiah yang dinotasikan dengan $P\left(a_{x|y z: \bar{n}|}\right)$ adalah [3]:

Berdasarkan persamaan (7.1), maka

$$
P\left(a_{x \mid y z: \overline{n \mid}}\right)=\frac{a_{x|y z: \bar{n}|}}{\ddot{a}_{x y z: \bar{n} \mid}}
$$

$$
P\left(a_{x \mid y z: \overline{n \mid}}\right)=\frac{a_{y z: \overline{n \mid}}-a_{x y z: \overline{n \mid}}}{\ddot{a}_{x y z: \bar{n} \mid}}
$$

b. Jika $(x)$ dan $(y)$ yang hidup bersamaan dengan status joint life, jika di antara $(x)$ dan $(y)$ ada yang meninggal dunia (yang manapun juga), pada akhir tahun polis tersebut jatuh tempo anuitas untuk $(z)$, nilai tunai anuitasnya dinotasikan dengan $a_{x y|z: \bar{n}|}$. Pembayaran premi tahunan untuk anuitas $a_{x y \mid z: \overline{n \mid}}$ sebesar 1 rupiah yang dinotasikan dengan $P\left(a_{x y|z: \bar{n}|}\right)$ adalah [5]:

$$
P\left(a_{x y|z: \bar{n}|}\right)=\frac{a_{x y \mid z: \overline{n \mid}}}{\ddot{a}_{x y z: \overline{n \mid}}} .
$$

Berdasarkan persamaan (7.2), maka

$$
P\left(a_{x y \mid z: \overline{n \mid}}\right)=\frac{a_{z: \bar{n} \mid}-a_{x y z: \bar{n} \mid}}{\ddot{a}_{x y z: \bar{n} \mid}} .
$$




\section{Contoh Aplikasi}

Perhitungan premi tahunan untuk pemegang asuransi jiwa dengan menggunakan anuitas reversionary akan diterapkan dalam contoh kasus sebagai berikut:

(1) Raffi sebagai suami yang berusia 45 tahun, beserta Mawar (istri) yang berusia 39 tahun, Sasa (anak) yang berusia 16 tahun mengikuti asuransi jiwa bersama berjangka dengan jangka waktu 25 tahun dengan uang pertanggungan sebesar Rp 100.000.000. Akan dihitung premi tahunan, jika:

a. Setelah 10 tahun mereka mendaftar pada program asuransi tersebut ternyata Raffi meninggal dunia, sehingga ahli waris mendapatkan santunan sebesar Rp. 100.000.000. Namun, karena kontrak asuransi masih ada selama 15 tahun lagi, maka menjadi kewajiban bagi Mawar dan Sasa untuk melanjutkan pembayaran premi dengan uang pertanggungan sebesar Rp 100.000.000 dengan status joint life. Jika dalam jangka waktu 15 tahun tersebut ternyata salah satu dari Mawar dan Sasa meninggal dunia maka ahli waris akan mendapatkan uang pertanggungan total sebesar Rp 200.000.000 (yang berasal dari uang pertanggungan kontrak anuitas reversionary sebesar $\mathrm{Rp}$ 100.000.000 ditambah dengan uang pertanggungan asuransi jiwa bersama pada saat kontrak disetujui sebesar Rp 100.000.000).

b. Setelah 10 tahun mereka mendaftar pada program asuransi tersebut ternyata Raffi meninggal dunia, sehingga ahli waris mendapatkan santunan sebesar Rp. 100.000.000. Namun, karena alasan tertentu premi hanya dilanjutkan oleh Sasa saja atas kesepakatan keluarga dengan uang pertanggungan sebesar Rp 100.000.000 hingga akhir tahun ke-25. Jika dalam jangka waktu 15 tahun tersebut ternyata Sasa meninggal dunia maka ahli waris akan mendapatkan uang pertanggungan total sebesar Rp 200.000.000 (yang berasal dari uang pertanggungan kontrak anuitas reversionary sebesar Rp 100.000.000 ditambah dengan uang pertanggungan asuransi jiwa bersama pada saat kontrak disetujui sebesar Rp 100.000.000).

Akan dihitung premi tahunan untuk kedua kasus diatas, yaitu:

a. Berdasarkan kasus pada poin (a) bahwa usia Raffi meninggal dunia, $x=55$ tahun, usia Mawar pada saat Raffi meninggal dunia, $y=49$ tahunn, dan usia Sasa pada saat Raffi meninggal dunia, $z=26$ tahun, sehingga jangka waktu yang tersisa, $n=15$ tahun. Uang pertanggungan setelah Raffi meninggal dunia, misalkan $R=R p .100 .000 .000$ dengan tingkat suku bunga $i=2,5 \%=0,025$.

Maka premi tahunan yang harus dibayar Mawar dan Sasa dengan uang pertanggungan $\mathrm{Rp}$ 100.000.000, yaitu:

$$
P\left(a_{x|y z: \bar{n}|}\right)=100.000 .000 \times \frac{a_{y z: \overline{n \mid}}-a_{x y z: \bar{n} \mid}}{\ddot{a}_{x y z: \bar{n} \mid}}
$$

Dengan menggunakan persamaan (5.4) dan (5.3), maka diperoleh: 
- Nilai anuitas hidup akhir berjangka $y z$

$$
\begin{aligned}
a_{y z: \bar{n} \mid} & =\frac{N_{y+1: z+1}-N_{y+n+1: z+n+1}}{D_{y z}}=\frac{N_{49+1: 26+1}-N_{49+15+1: 26+15+1}}{D_{49: 26}} \\
& =\frac{71696930648,4362-28589370920,8265}{3661982105,1199} \\
& =11,7716 .
\end{aligned}
$$

- Nilai anuitas hidup akhir berjangka $x y z$

$$
\begin{aligned}
a_{x y z: \bar{n} \mid} & =\frac{N_{x+1: y+1: z+1}-N_{x+n+1: y+n+1: z+n+1}}{D_{x y z}}, \\
& =\frac{N_{55+1: 49+1: 26+1}-N_{55+15+1: 49+15+1: 26+15+1}}{D_{55: 49: 26}}, \\
& =\frac{3893045886162130-925907791188019}{280860257189078}, \\
& =10,5645 .
\end{aligned}
$$

- Nilai anuitas hidup awal berjangka $x y z$

$$
\begin{aligned}
\ddot{a}_{x y z: \bar{n} \mid} & =\frac{N_{x y z}-N_{x+n: y+n: z+n}}{D_{x y z}}=\frac{N_{55: 49: 26}-N_{70: 64: 41}}{D_{55: 49: 26}}, \\
& =\frac{4173906143351210-1052554568103530}{280860257189078}, \\
& =11,1135 .
\end{aligned}
$$

Sehingga,

$$
\begin{aligned}
P\left(a_{x|y z: \bar{n}|}\right) & =100.000 .000 \times \frac{a_{y z: \overline{n \mid}}-a_{x y z: \bar{n} \mid}}{\ddot{a}_{x y z: \bar{n} \mid}}, \\
& =100.000 .000 \times \frac{a_{49: 26: \overline{15 \mid}}-a_{55: 49: 26: \overline{15 \mid}}}{\ddot{a}_{55: 49: 26: \overline{15 \mid}}}, \\
& =100.000 .000 \times \frac{11,7716-10,5645}{11,1135}, \\
& =\text { Rp.10.861.565. }
\end{aligned}
$$

Jadi, premi tahunan yang harus dibayar Mawar dan Sasa setelah Raffi meninggal dunia dengan uang pertanggungan $\mathrm{Rp} 100.000 .000$ adalah sebesar $\mathrm{Rp}$ 10.861 .565 .

b. Pada kasus poin (b) dapat pula dideskripsikan bahwa usia Raffi meninggal dunia, $x=55$ tahun, sia Mawar pada saat Raffi meninggal dunia, $y=49$ tahunn, dan usia Sasa pada saat Raffi meninggal dunia, $z=26$ tahun, sehingga jangka waktu yang tersisa, $n=15$ tahun. Uang pertanggungan setelah Raffi meninggal dunia, misalkan $R=\mathrm{Rp} 100.000 .000$ dengan tingkat suku bunga $i=2,5 \%=0,025$.

Maka premi tahunan yang harus dibayar Sasa dengan uang pertanggungan Rp 100.000.000, yaitu

$$
P\left(a_{x y|z: \bar{n}|}\right)=100.000 .000 \times \frac{a_{z: \bar{n} \mid}-a_{x y z: \bar{n}}}{\ddot{a}_{x y z: \bar{n} \mid}}
$$

dengan, 
- Nilai anuitas hidup akhir berjangka $z$.

$$
\begin{aligned}
a_{z: \bar{n} \mid} & =\frac{N_{z+1}-N_{z+n+1}}{D_{z}}=\frac{N_{26+1}-N_{26+15+1}}{D_{26}} \\
& =\frac{632844,21198640}{51540,7607804}, \\
& =12,2785 .
\end{aligned}
$$

- Nilai anuitas hidup akhir berjangka $x y z$ telah diperoleh sebelumnya, yaitu $a_{x y z: \bar{n}}=a_{55: 49: 26: \overline{15 \mid}}=10,5645$.

- Nilai anuitas hidup awal berjangka $x y z$ telah diperoleh sebelumnya, yaitu $\ddot{a}_{x y: \overline{n \mid}}=\ddot{a}_{55: 49: 26: \overline{15 \mid}}=11,1135$.

Sehingga,

$$
\begin{aligned}
P\left(a_{x y|z: \bar{n}|}\right) & =100.000 .000 \times \frac{a_{z: \bar{n} \mid}-a_{x y z: \bar{n} \mid}}{\ddot{a}_{x y z: \bar{n}}}=100.000 .000 \times \frac{a_{26: \overline{15 \mid}}-a_{55: 49: 26: \overline{15 \mid}}}{\ddot{a}_{55: 49: 26: \overline{15 \mid}}} \\
& =100.000 .000 \times \frac{12,2785-10,5645}{11,1135} \\
& =\operatorname{Rp} 15.422 .685
\end{aligned}
$$

Jadi, premi tahunan yang harus dibayar oleh Sasa setelah Raffi meninggal dunia dengan uang pertanggungan sebesar Rp 100.000.000 adalah sebesar Rp 15.422.685

\section{Kesimpulan}

Asuransi jiwa bersama joint life yang dikombinasikan dengan anuitas reversionary merupakan konrak asuransi yang dilanjutkan oleh peserta asuransi setelah salah satu dari peserta asuransi meninggal dunia dan ahli waris mendapatkan santunan, tetapi peserta yang masih hidup akan tetap melanjutkna pembayaran premi hingga akhir kontrak asuransi dengan status joint life. Pada dasarnya, premi yang harus dibayarkan peserta asuransi jiwa bergantung pada usia masuk peserta, besarnya uang pertanggungan dan suku bunga.

\section{Daftar Pustaka}

[1] Bowers, N.L., H.U. Gerber, D.A. Jones, dan C.J. Nesbitt. 1997. Actuarial Mathematics Second Edition. Illinois: The Society of Actuaries.

[2] Futami, Takashi. 1993.Matematika Asuransi Jiwa Bagian I . Tokyo: Incorporated Foundation Oriental Life Insurance Cultural Development Center.

[3] Futami, Takashi. 1994.Matematika Asuransi Jiwa Bagian II . Tokyo: Incorporated Foundation Oriental Life Insurance Cultural Development Center.

[4] Gerber, H.U. 1997. Life Insurance Mathematics Third Edition. Swiss: Swiis Association of Actuaries Zurich.

[5] Jordan Jr, C. W. 1991. Society of Actuaries' Textbook on Life Contingencies, Second Edition. Chicago: The Society of Actuaries.

[6] Larson R.E. dan E.A. Gaumnitz. 1951. Life Insurance Mathematics. New York: John Wiley and Sons, Inc 